\title{
URIC ACID AND COGNITION: WHAT IS THE CONNECTION?
}

\author{
Maura Palmery ${ }^{1}$, Raffaella Reggi ${ }^{1}$, and Ilaria Peluso ${ }^{2}$ \\ 'Department of Physiology and Pharmacology "V. Erspamer", Sapienza University of Rome, \\ Rome, Italy, and ${ }^{2}$ Center of Nutrition, Council for Agricultural Research and Economics (CREA-NUT), \\ Rome, Italy
}

Cognitive decline is one of the most frequent and disabling non motor features in ageing. The relationship between uric acid (UA) levels and cognitive impairment varies with dementia subtype. In this context, dysmetabolism, oxidative stress and neuroinflammation play a role in cognitive impairment and are all affected by UA. The mechanisms of neuroprotection against oxidative stresses include both the antioxidant activity against reactive oxygen species (ROS) and the induction of the gene expression of the antioxidant enzymes. On the other hand, hyperuricemia induces the production of ROS and inflammatory cytokines, leading to neuroinflammation and neurodegeneration. The increased brain gliosis could link neuroinflammation and dysmetabolism. Also the gender-related differences in the clinical features of cognitive impairment could be partly related to UA and should be taken into account for the "normal" range set for UA concentration. In conclusion, UA affects cognitive function, by interacting with neural, immune, cardiometabolic and, probably, adipose pathways and could be a target of the neuro-immuneadipose interactions. Biomed Rev 2016; 27: 51-57

Key words: antioxidant, dementia, gliosis, neurodegeneration, neuroprotection, obesity-related diseases, Alzheimer's disease, adipose tissue

\section{INTRODUCTION}

Uric acid (UA), the end product of purine metabolism in humans produced by hypoxanthine and xanthine under the catalysis of xanthine oxidase (XO), is a potent endogenous antioxidant in the extracellular environment (1). In LeschNyhan Disease, an inborn error of purine metabolism, the hypoxanthine-guanine phosphoribosyltransferase (HPRT) deficiency results in hyperuricaemia, urate nephrolithiasis, gout and cognitive impairment (2-4). On the other hand, gout is inversely associated with the risk of developing Alzheimer's disease (AD) (5). Therefore, there is still a considerable debate concerning whether UA is neuroprotective or neurotoxic.

\section{URIC ACID AND COGNITIVE DECLINE}

Cognitive decline is one of the most frequent and disabling non motor features in ageing and includes different subtypes, such as AD, mild cognitive impairment (MCI), Parkinson's disease $(\mathrm{PD})$, vascular dementia $(\mathrm{VaD})$ and mixed dementia

Received 21 November 2016, revised 7 December 2016, accepted 18 December 2016.

Correspondence to Ilaria Peluso, PhD; Center of Nutrition, Council for Agricultural Research and Economics (CREA-NUT), Via Ardeatina 546, 00178 Rome, Italy Tel.: +39-0651494560 Fax: +39-0651494550

E-mail: i.peluso@tiscali.it; ilaria.peluso@crea.gov.it 
(MD) (6-12). Although higher levels of UA were generally associated with slower cognitive decline (7-12) and UA has been suggested as an inverse biomarker for dementia $(9,10)$, results of a recent meta-analysis suggest that the relationship between UA and cognitive impairment varies with dementia subtype (12). Subgroup analyses for patients with AD, PD, $\mathrm{MCI}, \mathrm{VaD}$ and $\mathrm{MD}$ revealed that, compared to controls, UA was lower in AD (SDM -0.33), PD (SDM -0.67), but not in MCI (SMD -0.24), VaD (SDM -0.05) or MD (SDM 0.19) (12) (Fig. 1). In particular, authors pointed out that the relationship between UA and cognitive impairment may differ in patients with $\mathrm{VaD}$ compared to other dementia subtypes (12). In this context, it is well known that hyperuricemia is positively associated with hypertension, arterial intima-media thickness, impaired brachial artery flow-mediated dilation and aortic dilatation in patients with ascending aortic aneurysms (13-16) (Fig. 1). Uric acid is directly correlated with age and increased after hypoxia-reoxygenation, leading to endothelial cell death and endothelium-dependent relaxation impairment $(17,18)$. High UA is associated with increased cerebral ischemia (CI) (Fig. 1) and it has been suggested that severity of CI might mediate the association between UA and cognitive dysfunction (19). However, although diastolic blood pressure was consistently correlated with plasma amyloid beta $(A \beta)$

$\begin{array}{lll}\text { Weight loss } & \text { Obesity } \\ \text { Low cholesterol } & & \text { High cholesterol } \\ & & \text { T2D }\end{array}$

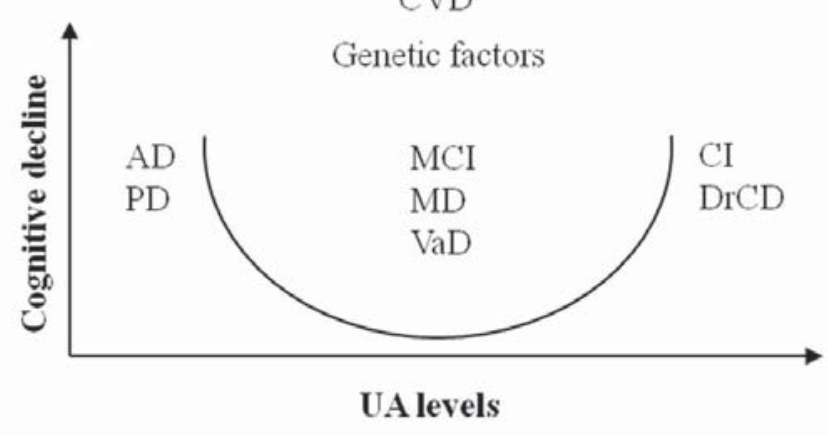

Figure 1. Uric acid, dysmetabolism and cognitive decline. AD: Alzheimer's disease; CI: cerebral ischemia; CVD: cardiovascular diseases; DrCD: Diabetes related cognitive dysfunction; MCI: mild cognitive impairment; MD: mixed dementia; PD: Parkinson's disease; T2D: type 2 diabetes; $U A$ : uric acid; VaD: vascular dementia. levels $(\mathrm{r}=-0.19, \mathrm{p}=0.032)$ and $\mathrm{A} \beta 40$ was associated with UA ( $\mathrm{r}=0.285, \mathrm{p}=0.001)$ (20) low UA levels in patients with preexisting cardiovascular disease were associated with poorer cognitive function a decade later (21).

\section{DYSMETABOLISM AND COGNITIVE DECLINE}

The relationship between obesity, dysmetabolism and cognitive decline in elderly is unclear.

Although high level of UA are associated with obesity, metabolic syndrome, type 2 diabetes (T2D), kidney and cardiometabolic diseases (22-25), weight loss occurs frequently in patients with $\mathrm{AD}$ (26) and lower UA levels are linked to cognitive dysfunction in elderly (27).

Higher diastolic blood pressure, body mass index and abdominal obesity index, as well as higher serum glycated hemoglobin, triglycerides, cholesterol and UA are associated with MCI (28) and/or diabetes related cognitive dysfunction (29) (Fig. 1). However, it has also been reported that MCI patients had lower plasma total cholesterol, low-density lipoprotein cholesterol, and high-density lipoprotein cholesterol than control subjects (30) (Fig. 1). In this context, it must be taken into account that genetic susceptibility plays a role. For example, the genetic risk factor Apolipoprotein E (ApoE) $\varepsilon 4$ allele $(\mathrm{OR}=5.90)$ was associated with an increased risk of $\mathrm{AD}(31)$ and there is an interaction between oxidative stress and ApoE genotype in the development of the neurodegeneration $(32,33)$.

\section{URIC ACID AND OXIDATIVE STRESS}

Oxidative stress is the result of the imbalance between reactive oxygen species (ROS) and antioxidant defense (34). Systemic oxidative stress is common in patients with cognitive impairment and markers of lipid peroxidation are elevated and total antioxidant capacity is decreased in AD and MCI (35).

The effect of UA on oxidative stress depends on its concentration. UA at concentrations below the saturation level for urate precipitation $(6.0 \mathrm{mg} / \mathrm{dl})$ inhibits significantly oxidations caused by the Fenton reaction (36) and by the peroxyl radicals (37) (Fig. 2). On the other hand, UA induces the nuclear translocation of the nuclear factor (erythroidderived 2)-like 2 (Nrf2) protein in primary astrocytic cultures (38), leading to the transcription of antioxidant genes through the antioxidant responsive elements (ARE) (Fig. 2). Antioxidant enzymes, such as superoxide dismutase (SOD), catalase (CAT), glutathione peroxidase (GPX) and glutathione reductase (GR), and glutathione (GSH) are major antioxidants at the cellular level (39). Superoxide dismutase 


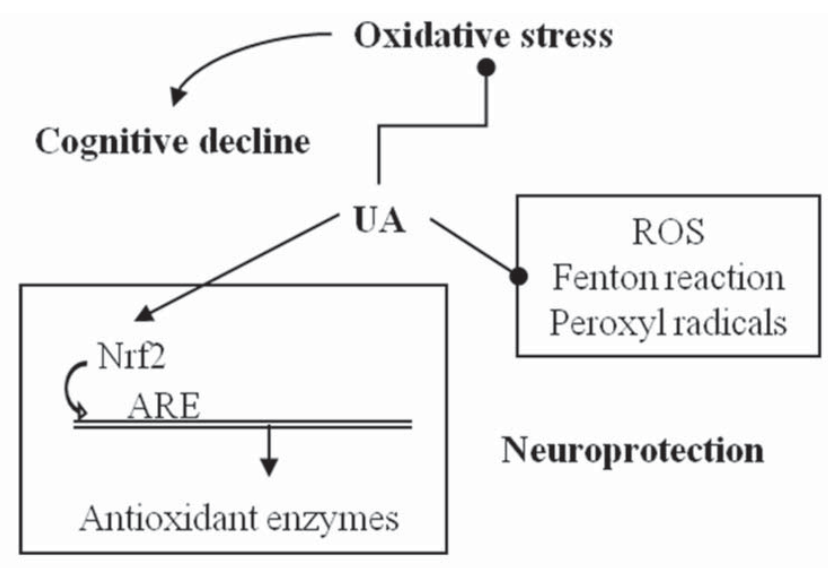

Figure 2. Uric acid and neuroprotection against oxidative stress. ARE: antioxidant responsive elements; Nrf2: nuclear translocation of the nuclear factor (erythroid-derived 2)-like 2; ROS: reactive oxygen species; UA: uric acid.

catalyzes the one-electron dismutation of superoxide into hydrogen peroxide and oxygen, catalase then operates the two electron-dismutation into oxygen and water (39). Glutathione peroxidase is involved in hydrogen peroxide removal and in the conversion of lipid hydroperoxides to their corresponding alcohols, through the oxidation of GSH to glutathione disulphide (GSSG), which is reduced back to GSH by the GR (39). The reduction of the Nrf2 ubiquitination and degradation has been suggested as the mechanisms of neuroprotection on dopaminergic cells against oxidative stresses (40).

\section{URIC ACID AND NEUROINFLAMMATION}

Although, low levels of UA are detrimental to the neurons, UA has been identified as an endogenous danger signal for immune system $(41,42)$. In particular, hyperuricemia may lead to the formation of monosodium urate crystals (MSU), the latter activating monocytes via the inflammasome $(43,44)$, in part through Toll-like receptor 4 (TLR4)/CD14 pathway (44) (Fig. 3). Besides, in response to MSU, the neutrophils recruited to sites of inflammation undergo oxidative burst (45). The main enzymes, operating during oxidative burst, are NADPH oxidase (NOX), myeloperoxidase (MPO) and nitric oxide synthase (NOS) (46), producing superoxide, hypochlorous acid $(\mathrm{HClO})$ and nitric oxide $(\mathrm{NO})$, respectively (Fig. 3). NADPH oxidase (47, 48), MPO (49-51) and NOS (52) have been involved in neurodegenerative disorders (Fig. 3). In this context, the activation of microglia, the resident macrophages of the central nervous system, has a central role

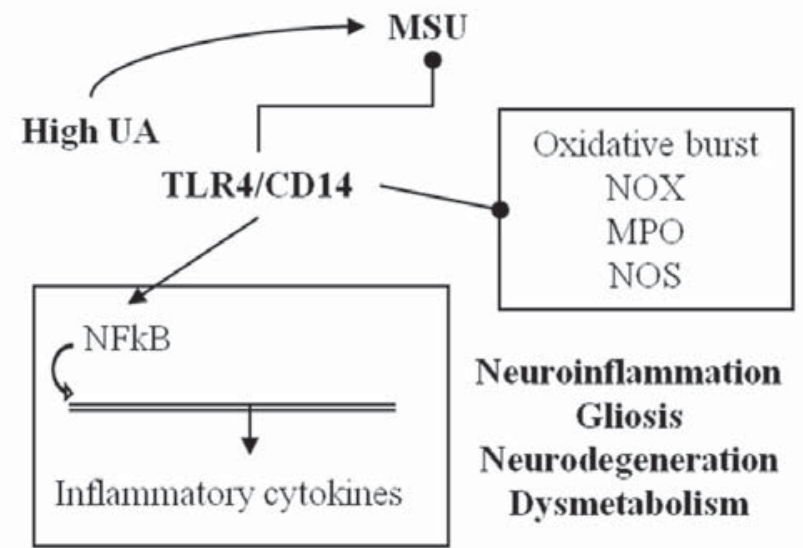

Figure 3. Uric acid, neuroinflammation, neurodegeneration and dysmetabolism. MPO: myeloperoxidase; MSU: monosodium urate crystals; NOS: nitric oxide synthase; NOX: NADPH oxidase; TLR4: Toll-like receptor 4; UA: uric acid.

in neuroinflammation and ROS-mediated neurodegeneration (53). Microglia induce neurodegeneration also by secreting inflammatory cytokines, such as tumor necrosis factoralpha (TNF- $\alpha$ ), in response to the synergistic induction by chromogranin A (CGA), beta-amyloid ( $\beta \mathrm{A})$ and interferongamma (IFN- $\gamma$ ) (54). Recent results in animal models suggest that a high-UA diet increases gliosis by inducing the expression of proinflammatory cytokines, through the Tolllike TLR4/nuclear factor (NF)- $\mathrm{KB}$ pathway (55) (Fig. 3). Besides, the high-UA diet-induced NF- $\mathrm{KB}$ activation triggered the expression of proinflammatory cytokines and increased gliosis in the hypothalamus, linking neuroinflammation and dysmetabolism (56) (Fig. 3). In fact, the rats treated with UA showed dyslipidemia, increased blood pressure, higher glucose and insulin concentrations than control rats (56).

\section{URIC ACID, GENDER DIFFERENCES AND COGNITIVE DECLINE}

The existence of substantial gender-related differences in the clinical features of cognitive impairment could be partly related to UA. Serum UA showed an inverse association with cognitive function among aged women, but not among men, and the association was amplified by the presence of cardiovascular disease, suggesting that women may be particularly vulnerable to the elevated UA (57-59). In fact, the association of serum UA with cadiovascular risk factor $(60)$, metabolic syndrome $(60,61)$ and T2D $(62)$ is genderspecific and more pronounced in women. From that, although the "normal" range set for UA concentration is still disputed, 
gender specific normal values are always applied (60-64). However, it has been reported that in nonagenarian and centenarian men, the higher level of UA is related to a lower risk of cognitive impairment compared to women $(65,66)$.

Intriguingly, it was reported that adipose tissue may secrete UC related to obesity (67), the latter being associated with Alzeihmer's disease (68). In such an adipocentric approach, UA could play a role in the neuro-immune-adipose interactions referred to as triactome (69).

Taken together, UA may affect cognitive function by interacting with neural, immune, cardiometabolic and, probably, adipose pathways.

Conflict of interest statement: The authors declare that the research was conducted in the absence of any commercial or financial relationships that could be construed as a potential conflict of interest.

\section{REFERENCES}

1. Peluso I, Raguzzini A. Salivary and urinary total antioxidant capacity as biomarkers of oxidative stress in humans. Pathol Res Int 2016; 2016: 5480267. DOI: 10.1155/2016/5480267.

2. Bayat A, Christensen M, Wibrand F, Duno M, Lund A. Mild Lesch-Nyhan disease in a boy with a null mutation in HPRT1: An exception to the known genotypephenotype correlation. JIMD Rep 2015; 18:135-137. DOI: 10.1007/8904_2014_368.

3. de Gemmis P, Anesi L, Lorenzetto E, Gioachini I, Fortunati E, Zandonà G, et al. Analysis of the HPRT1 gene in 35 Italian Lesch-Nyhan families: 45 patients and 77 potential female carriers. Mutat Res 2010; 692:1-5. DOI: 10.1016/j.mrfmmm.2010.07.003.

4. Torres RJ, Puig JG. Hypoxanthine-guanine phosophoribosyltransferase (HPRT) deficiency: LeschNyhan syndrome. Orphanet J Rare Dis 2007; 2:48. DOI: 10.1186/1750-1172-2-48.

5. Lu N, Dubreuil M, Zhang Y, Neogi T, Rai SK, Ascherio A, et al. Gout and the risk of Alzheimer's disease: a population-based, BMI-matched cohort study. Ann Rheum Dis 2016;75: 547-551. DOI: 10.1136/ annrheumdis-2014-206917.

6. Pellecchia MT, Savastano R, Moccia M, Picillo M, Siano $\mathrm{P}$, Erro R, et al. Lower serum uric acid is associated with mild cognitiveimpairment in early Parkinson's disease: a 4-year follow-up study. J Neural Transm (Vienna) 2016; 123: 1399-1402. DOI: 10.1007/s00702-016-1622-6.
7. Picillo M, Santangelo G, Moccia M, Erro R, Amboni M, Prestipino E, et al. Serum uric acid is associated with apathy in early, drug-naïve Parkinson's disease. J Neural Transm (Vienna) 2016; 123: 371-377. DOI: 10.1007/ s00702-015-1502-5.

8. Moccia M, Picillo M, Erro R, Vitale C, Longo K, Amboni $\mathrm{M}$, et al. Is serum uric acid related to non-motor symptoms in de-novo Parkinson's disease patients? Parkinsonism Relat Disord 2014; 20: 772-775. DOI: 10.1016/j. parkreldis.2014.03.016.

9. Delgado-Alvarado M, Gago B, Navalpotro-Gomez I, Jiménez-Urbieta H, Rodriguez-Oroz MC. Biomarkers for dementia and mild cognitive impairment in Parkinson's disease. Mov Disord 2016; 31: 861-881. DOI: 10.1002/ mds. 26662

10. Ye BS, Lee WW, Ham JH, Lee JJ, Lee PH, Sohn YH. Does serum uric acid act as a modulator of cerebrospinal fluid Alzheimer's disease biomarker related cognitive decline? Eur J Neurol 2016; 23: 948-957. DOI: 10.1111/ ene. 12969

11. Al-khateeb E, Althaher A, Al-khateeb M, Al-Musawi H, Azzouqah O, Al-Shweiki S, et al. Relation between uric acid and Alzheimer's disease in elderly Jordanians. $J$ Alzheimers Dis 2015; 44: 859-865. DOI: 10.3233/JAD142037

12. Khan AA, Quinn TJ, Hewitt J, Fan Y, Dawson J. Serum uric acid level and association with cognitive impairment and dementia: systematic review and meta-analysis. Age (Dordr) 2016; 38: 16. DOI 10.1007/s11357-016-9871-8

13. Kostka-Jeziorny K, Uruski P, Tykarski A. Effect of allopurinol on blood pressure and aortic compliance in hypertensive patients. Blood Press 2011; 20: 104-110. DOI: 10.3109/08037051.2010.532323.

14. Gür M, Sahin DY, Elbasan Z, Kalkan GY, Yıldız A, Kaya Z, et al. Uric acid and high sensitive Creactive protein are associated with subclinical thoracic aortic atherosclerosis. J Cardiol 2013; 61: 144-148. DOI: 10.1016/j.jjcc.2012.08.023.

15. Erdogan D, Gullu H, Caliskan M, Yildirim E, Bilgi M, Ulus $\mathrm{T}$, et al. Relationship of serum uric acid to measures of endothelial function and atherosclerosis in healthy adults. Int J Clin Pract 2005; 59: 1276-1282. DOI: 10.1111/j.1742-1241.2005.00621.x

16. Esen AM, Akcakoyun M, Esen O, Acar G, Emiroglu Y, Pala $\mathrm{S}$, et al. Uric acid as a marker of oxidative stress in dilatation of the ascending aorta. Am J Hypertens 2011; 24(2): 149-54. doi: 10.1038/ajh.2010.219. 
17. Aranda R, Doménech E, Rus AD, Real JT, Sastre J, Viña J, Pallardó FV. Age-related increase in xanthine oxidase activity in human plasma and rat tissues. Free Radic Res 2007; 41: 1195-1200. DOI: 10.1080/10715760701481461

18. Yokoyama S, Korthuis RJ, Benoit JN. Hypoxiareoxygenation impairs endothelium-dependent relaxation in isolated rat aorta. Am J Physiol 1996; 270(5Pt2): R112631. PMID: 8928916

19. Vannorsdall TD, Jinnah HA, Gordon B, Kraut M, Schretlen DJ. Cerebral ischemia mediates the effect of serum uric acid oncognitive function. Stroke 2008; 39: 3418-3420. DOI: 10.1161/STROKEAHA.108.521591

20. Ruiz A, Pesini P, Espinosa A, Pérez-Grijalba V, Valero $\mathrm{S}$, Sotolongo-Grau O, et al. Blood amyloid beta levels in healthy, mild cognitive impairment and Alzheimer's disease individuals: replication of diastolic blood pressure correlations and analysis of critical covariates. PLoS One. 2013; DOI: 10.1371/journal.pone.0081334

21. Molshatzki N, Weinstein G, Streifler JY, Goldbourt U, Tanne D. Serum uric acid and subsequent cognitive performance in patients with pre-existing cardiovascular disease. PLoS One 2015; DOI: 10.1371/journal. pone.0120862

22. Yadav D, Lee ES, Kim HM, Lee EY, Choi E, Chung CH. Hyperuricemia as a potential determinant of metabolic syndrome. J Lifestyle Med 2013; 3: 98-106. PMID: 26064845

23. Soltani Z, Rasheed K, Kapusta DR, Reisin E. Potential role of uric acid in metabolic syndrome, hypertension, kidney injury, and cardiovascular diseases: is it time for reappraisal? Curr Hypertens Rep 2013;15(3):175-81. DOI: $10.1007 / \mathrm{s} 11906-013-0344-5$.

24. Li C, Hsieh MC, Chang SJ. Metabolic syndrome, diabetes, and hyperuricemia. Curr Opin Rheumatol 2013; 25: 210 216. DOI: 10.1097/BOR.0b013e32835d951e.

25. Chaudhary K, Malhotra K, Sowers J, Aroor A. Uric Acid - key ingredient in the recipe for cardiorenal metabolic syndrome. Cardiorenal Med 2013; 3: 208-220. DOI: 10.1159/000355405.

26. Tamura BK, Masaki KH, Blanchette P. Weight loss in patients with Alzheimer's disease. J Nutr Elder 2007; 26: 21-38. DOI: 10.1300/J052v26n03_02

27. Méndez-Hernández E, Salas-Pacheco J, Ruano-Calderón L, Téllez-Valencia A, Cisneros-Martínez J, Barraza-Salas $\mathrm{M}$, et al. Lower uric acid linked with cognitive dysfunction in the elderly. CNS Neurol Disord Drug Targets 2015; 14: 564-566. DOI: 10.2174/1871527314666150430161659.
28. Yao Q, Jiang GX, Zhou ZM, Chen JM, Cheng Q. Metabolic syndrome and mild cognitive impairment: A case-control study among elderly in a Shanghai Suburb. J Alzheimers Dis 2016; 51:1175-1182. DOI: 10.3233/ JAD-150920.

29. Zhang L, Li M, Zhan L, Lu X, Liang L, Su B, et al. Plasma metabolomic profiling of patients with diabetes-associated cognitive decline. PLoS One 2015; DOI: 10.1371/journal. pone.0126952.

30. Yuan L, Liu J, Ma W, Dong L, Wang W, Che R, et al. Dietary pattern and antioxidants in plasma and erythrocyte in patients with mild cognitive impairment from China. Nutrition 2016; 32: 193-198. DOI: 10.1016/j. nut.2015.08.004.

31. Agarwal R, Tripathi CB. Association of apolipoprotein E genetic variation in Alzheimer's disease in Indian population: a meta-analysis. Am J Alzheimers Dis Other Demen 2014; 29: 575-82. DOI: 10.1177/1533317514531443.

32. Zito G, Polimanti R, Panetta V, Ventriglia M, Salustri $\mathrm{C}$, Siotto MC, et al. Antioxidant status and APOE genotype as susceptibility factors for neurodegeneration in Alzheimer's disease and vascular dementia. Rejuvenation Res 2013; 16: 51-56. DOI: 10.1089/ rej.2012.1383.

33. Marcourakis T, Bahia VS, Kawamoto EM, Munhoz CD, Gorjão R, Artes R, et al. Apolipoprotein E genotype is related to nitric oxide production in platelets. Cell Biochem Funct 2008; 26: 852-858. DOI: 10.1002/cbf.1516

34. Valko M, Leibfritz D, Moncol J, Cronin MT, Mazur M, Telser J. Free radicals and antioxidants in normal physiological functions and human disease. Int $J$ Biochem Cell Biol 2007; 39: 44-84. DOI: 10.1016/j. biocel.2006.07.001

35. Schrag M, Mueller C, Zabel M, Crofton A, Kirsch WM, Ghribi O, et al. Oxidative stress in blood in Alzheimer's disease and mild cognitiveimpairment: a meta-analysis. Neurobiol Dis 2013; 59:100-110. DOI: 10.1016/j. nbd.2013.07.005

36. Waugh WH. Inhibition of iron-catalyzed oxidations by attainable uric acid and ascorbic acid levels: therapeutic implications for Alzheimer's disease and late cognitive impairment. Gerontology 2008; 54:238-243. DOI: 10.1159/000122618

37. Muraoka S, Miura T. Inhibition by uric acid of free radicals that damage biological molecules. Pharmacol Toxicol 2003; 93:284-289. DOI: 10.1111/j.1600-0773.2003. pto930606.x 
38. Bakshi R, Zhang H, Logan R, Joshi I, Xu Y, Chen X, Schwarzschild MA. Neuroprotective effects of urate are mediated by augmenting astrocytic glutathione synthesis and release. Neurobiol Dis 2015; 82: 574-579. DOI: 10.1016/j.nbd.2015.08.022.

39. Peluso I, Manafikhi H, Palmery M. Free radicals generated by post-prandial oxidative burst in the early alterations of vascular contractility. Clin Immunol Endocr Metab Drugs 2014; 1:27-45. DOI: 10.2174/221270700101140 721000925.

40. Zhang N, Shu HY, Huang T, Zhang QL, Li D, Zhang GQ, et al. Nrf2 signaling contributes to the neuroprotective effects of urate against 6-OHDA toxicity. PLoS One 2014; DOI: 10.1371/journal.pone.0100286

41. Shi Y, Evans JE, Rock KL. Molecular identification of a danger signal that alerts the immune system to dying cells. Nature 2003; 425:516-521. DOI: 10.1038/nature01991.

42. Fang P, Li X, Luo JJ, Wang H, Yang XF. A double-edged sword: Uric acid and neurological disorders. Brain Disord Ther 2013; 2:109. DOI: 10.4172/2168-975X.1000109.

43. Krishnan E. Inflammation, oxidative stress and lipids: the risk triad for atherosclerosis in gout. Rheumatology (Oxford) 2010; 49:1229-1238. DOI: 10.1093/ rheumatology/keq037.

44. So A. Developments in the scientific and clinical understanding of gout. Arthritis Res Ther 2008; 10:221. DOI: $10.1186 /$ ar2509.

45. Schauer C, Janko C, Munoz LE, Zhao Y, Kienhöfer D, Frey B, et al. Aggregated neutrophil extracellular traps limit inflammation by degrading cytokines and chemokines. Nat Med 2014; 20: 511-517. DOI: 10.1038/ nm.3547.

46. Peluso I, Manafikhi H, Reggi R, Palmery M. Interference of flavonoids with fluorescent intracellular probes: methodological implications in the evaluation of the oxidative burst by flow cytometry. Cytometry A 2014; 85 : 663-677. DOI: 10.1002/cyto.a.22490.

47. Choi DH, Lee KH, Kim JH, Seo JH, Kim HY, Shin CY, et al. NADPH oxidase 1, a novel molecular source of ROS in hippocampal neuronal death in vascular dementia. Antioxid Redox Signal 2014; 21:533-550. DOI: 10.1089/ ars.2012.5129

48. Bruce-Keller AJ, Gupta S, Parrino TE, Knight AG, Ebenezer PJ, Weidner AM, et al. NOX activity is increased in mild cognitive impairment. Antioxid Redox Signal 2010; 12:1371-1382. DOI: 10.1089/ars.2009.2823

49. Yap YW, Whiteman M, Cheung NS. Chlorinative stress: an under appreciated mediator of neurodegeneration? Cell Signal 2007; 19: 219-228. DOI: 10.1016/j. cellsig.2006.06.013.

50. Pope SK, Kritchevsky SB, Ambrosone C, Yaffe K, Tylavsky F, Simonsick EM, et al. Myeloperoxidase polymorphism and cognitive decline in older adults in the Health, Aging, and Body Composition Study. Am J Epidemiol 2006; 163: 1084-1090. DOI: 10.1093/aje/ kwj146

51. Choi DK, Pennathur S, Perier C, Tieu K, Teismann P, $\mathrm{Wu} \mathrm{DC}$, et al. Ablation of the inflammatory enzyme myeloperoxidase mitigates features of Parkinson's disease in mice. J Neurosci 2005; 25:6594-6600. DOI: 10.1523/ JNEUROSCI.0970-05.2005

52. Jones NC, Constantin D, Gibson CL, Prior MJ, Morris PG, Marsden CA, et al. Detrimental role for nitric oxide synthase-2 in the pathology resulting from acute cerebral injury. J Neuropathol Exp Neurol 2004; 63:708-720. DOI: 10.1093/jnen/63.7.708.

53. Barger SW, Goodwin ME, Porter MM, Beggs ML. Glutamate release from activated microglia requires the oxidative burst and lipid peroxidation. J Neurochem 2007; 101: 1205-1213. DOI: 10.1111/j.1471-4159.2007.04487.x.

54. Twig G, Graf SA, Messerli MA, Smith PJ, Yoo SH, Shirihai OS. Synergistic amplification of beta-amyloidand interferon-gamma-induced microglial neurotoxic response by the senile plaque component chromogranin A. Am J Physiol Cell Physiol 2005; 288: C169-175. DOI: 10.1152/ajpcell.00308.2004.

55. Shao X, Lu W, Gao F, Li D, Hu J, Li Y, et al. Uric acid induces cognitive dysfunction through hippocampal inflammation in rodents and humans. $J$ Neurosci 2016; 36:10990-11005. DOI: 10.1523/JNEUROSCI.1480-16.2016.

56. Lu W, Xu Y, Shao X, Gao F, Li Y, Hu J, et al. Uric acid produces an inflammatory response through activation of NF- $\mathrm{BB}$ in the hypothalamus: implications for the pathogenesis of metabolic disorders. Sci Rep 2015; 5:12144. DOI: 10.1038/srep12144.

57. Perna L, Mons U, Schöttker B, Brenner H. Association of cognitive function and serum uric acid: Are cardiovascular diseases a mediator among women? Exp Gerontol 2016;81:37-41. DOI: 10.1016/j.exger.2016.04.017.

58. Cicero AF, Desideri G, Grossi G, Urso R, Rosticci M, D'Addato S, et al. Serum uric acid and impaired cognitive function in a cohort of healthy young elderly: data from the Brisighella Study. Intern Emerg Med 2015; 10:25-31. DOI: $10.1007 / \mathrm{s} 11739-014-1098-\mathrm{z}$. 
59. Vannorsdall TD, Kueider AM, Carlson MC, Schretlen DJ. Higher baseline serum uric acid is associated with poorer cognition but not rates of cognitive decline in women. Exp Gerontol 2014; 60:136-9. DOI: 10.1016/j. exger.2014.10.013.

60. Rodrigues SL, Baldo MP, Capingana P, Magalhães P, Dantas EM, Molina Mdel C, et al. Gender distribution of serum uric acid and cardiovascular risk factors: population based study. Arq Bras Cardiol 2012; 98:13-21. DOI: 10.1590/S0066-782X2011005000116.

61. Zhang ML, Gao YX, Wang X, Chang H, Huang GW. Serum uric acid and appropriate cutoff value for prediction of metabolic syndrome among Chinese adults. J Clin Biochem Nutr 2013; 52:38-42. DOI: 10.3164/jcbn.12-65.

62. Kawamoto R, Tabara Y, Kohara K, Kusunoki T, Abe M, Miki T. Serum uric acid is more strongly associated with impaired fasting glucose in women than in men from a community-dwelling population. PLoS One 2013; DOI: 10.1371/journal.pone.0065886.

63. Desideri G, Castaldo G, Lombardi A, Mussap M, Testa A, Pontremoli R, et al. Is it time to revise the normal range of serum uric acid levels? Eur Rev Med Pharmacol Sci 2014; 18:1295-1306. PMID: 24867507
64. Grassi D, Pontremoli R, Bocale R, Ferri C, Desideri G. Therapeutic approaches to chronic hyperuricemia and gout. High Blood Press Cardiovasc Prev 2014; 21: 243250. DOI: 10.1007/s40292-014-0051-6.

65. Li J, Dong BR, Lin P, Zhang J, Liu GJ. Association of cognitive function with serum uric acid level among Chinese nonagenarians and centenarians. Exp Gerontol 2010; 45:331-335. DOI: 10.1016/j.exger.2010.01.005.

66. Du N, Xu D, Hou X, Song X, Liu C, Chen Y, et al. Inverse association between serum uric acid levels and Alzheimer's disease risk. Mol Neurobiol 2016; 53:25942599. DOI: $10.1007 / \mathrm{s} 12035-015-9271-6$

67. Nishizawa H, Tochino Y, Nakatsuji H, Selimoto R, Nagao $\mathrm{H}$, et al. Uric acid secretion from adipose tissue and its increase in obesity. J Biol Chem 2013; 288: 27138-27149. DOI: $10.1074 /$ jbc.M113.485094

68. Aloe L, Tonchev AB, Maucher A, Fiore M, Zhelezov MD, Chaldakov GN. Adipobiology of the brain: From brain diabetes to adipose Alzheimer's disease. Adipobiology 2015; 7: 37-42.

69. Chaldakov GN, Fiore M, Ghenev PI, Beltowski J, Ranćić G, Tunçel N, Aloe L. Triactome: neuro-immune-adipose interactions. Implication in vascular biology. Front Immunol 2014; 5: 130. DOI: 10.3389/fimmu.2014.00130 